\title{
Creating Inclusive Cultures for Women in Automation and Information Technology Careers and Occupations
}

\author{
Darrell Norman Burrell, The Florida Institute of Technology, Melbourne, USA \\ (iD https://orcid.org/0000-0002-4675-9544 \\ Dawn Lee Diperi, American InterContintental University, Schaumburg, USA \\ iD https://orcid.org/0000-0001-6165-3732 \\ Rachel M. Weaver, Western Governors University, Salt Lake City, USA \\ (iD) https://orcid.org/0000-0003-1088-8878
}

\begin{abstract}
Automation will be central to the next phase of business technology transformation, driving new levels of customer value such as faster delivery of products, higher quality and dependability, deeper personalization, and greater convenience. This business transformation phase will require workers with new skills at all levels. There are significant shortages of women in leadership job roles in information technology and automation. There are also significant disparities with pay and opportunities for women in those fields. As a result, it is critical to understand the organizational cultural change strategies that information technology (IT) and automation companies can make to employ more females in information technology and automation positions and address gender pay issues and gender exclusivity issues currently existing in today's workplace. This article intends to influence the world of practice through the execution of a literature review content analysis.
\end{abstract}

\section{KEYWORDS}

Diversity and Inclusion, Gender Equity, Women in Automation, Women in Leadership, Women in Technology

\section{INTRODUCTION}

Research has shown that companies in the top $25 \%$ for gender diversity are more likely to outperform than those that are not (DeLeon, 2014). Gender diversity has consistently been proven as a critical element in helping businesses gain a competitive advantage (Burrell, 2019). However, as Mariah DeLeon (2014) explains in her article "How to Recruit More Female Executives," "Women make up $61 \%$ of the U.S. workforce, earn almost $60 \%$ of all undergraduate degrees and $37 \%$ of all MBAs, yet companies continue to lag in placing females in executive positions." Though the advantages of employing and promoting females into all layers of an organization are likely to contribute to the

This article, originally published under IGI Global's copyright on April 1, 2020 will proceed with publication as an Open Access article starting on February 1, 2021 in the gold Open Access journal, International Journal of Business Strategy and Automation (converted to gold Open Access January 1, 2021), and will be distributed under the terms of the Creative Commons Attribution License (http://creativecommons.org/licenses/by/4.0/) which permits unrestricted use, distribution, and production in any medium, provided the author of the original work and original publication source are properly credited. 
growth and financial success, businesses continue to struggle in making gender diversity a reality (Burrell, 2019). Companies often fail to promote or hire women in executive-level positions, primarily in the automation and technology industries where women are grossly underrepresented. According to Ahuja (2002), it is more important than ever to determine the factors that prevent women from entering automation and technology fields and progressing to executive-level positions.

Kuschel (2019) posited that one of the major contributing factors of the gender gap is the timing conflict between careers and motherhood. When technology companies look to employ women and satisfy their gender and diversity quotas, it may be wise to examine some of the strategies women implement in tech start-ups (Kuschel, 2019). Women-owned businesses may foster, nurture and develop their female employees by providing flex time and a healthy work-life balance that, in turn, positively affect the family unit and, therefore, employees of both genders (Kuschel, 2019). In some European countries, women receive more maternity leave than in the United States. In fall 2021, Finland's total paid parental allowance will increase to 14 months, including 164 days per parent, and Sweden has the most generous leave, which equates to 240 days per parent. Finland currently offers fathers the same parental consent as mothers, and in Sweden, nearly all fathers take paternal leave (Mussino, Tervola, \& Duvander, 2019). In the United States, some companies offer paternity leave, yet a gross majority of new fathers decline to take it, leaving the burden of early infant childcare on the mother (Mussino, Tervola, \& Duvander, 2019). The practice of providing extended paternity leave is rarely implemented in the United States, making it harder for the woman who may bear the brunt of childcare while also trying to enter, re-enter or progress in their career.

Women often feel they need to hide their desires to become mothers when hired and often significantly delay maternity to focus on their information technology (IT) and automation careers (Kuschel, 2019). Technology and business automation are still two of the most under-represented industries in female leadership, making the culture decidedly patriarchal (Burrell, 2019). Work-life balance benefits both genders, especially when it comes to the responsibilities of raising a family. Failure to produce flexible work options has dire consequences for all families (Ashcraft, McLain \& Eger, 2016). Female workers in the technology sector face several challenges. Many of them work more than 100 hours per week, need to be available 24/7, work or manage colleagues in multiple time zones, and feel overwhelming pressure to put in more face to face time (Hewlett et al., 2008). Such occupational stresses put a burden on the family unit and affect both partners in a relationship. Managing competing life responsibilities, such as family care, can be a challenge in business automation and technology. Women in these organizational cultures may feel penalized for having a family by being given less responsibility or less visible roles within an organization (Ashcraft, McLain \& Eger, 2016). Simard et al. (2008) found that only 7.3\% of mid-level technology industry workers agreed that successful personnel in IT are family-oriented, and over $60 \%$ of these same men and women self-identify with being family-oriented. This disparity can have real implications for losing top talent, as the industry as a whole is not known for implementing work-life balance practices.

Latin American women in technology and automation have more education and are part of the upper-middle socioeconomic status (Kuschel and Labra 2018) but are also a part of a group of women that has lower fertility rates (Adsera and Menendez 2011). Furthermore, Latin American women in the tech sector may be less influenced by macho culture (Susaeta et al. 2013). Women of color are especially underrepresented in technology and automation careers (Burrell, 2019). According to Ashcraft, McLain, and Eger (2016), the percentage of computing occupations held by women in 2015 include the following staggering statistics: White American women occupy $16 \%$ of all careers in computing, Asian American women occupy 5\%, African American women occupy $3 \%$ and Latin American women occupy only $1 \%$. What is even more alarming is that these numbers have been moving on a downward trend since 1991 (Ashcraft, McLain, \& Eger, 2016). The point in which women tend to quit is at midpoint or mid-career, which is defined as having between 1020 years of experience (Ashcraft, McLain, \& Eger; 2016). "One large-scale study found that after about 12 years, approximately 50 percent of women had left their jobs in technology, engineering, 
and automation fields" (Glass, Sassler, Levitte \& Michelmore, 2013). Investigating this critical time in a women's career trajectory and the accompanying societal, work, and family expectations can be beneficial to finding solutions to retain women in technology roles and nurture and mentor them to fulfill executive-level positions (Burrell, 2019). Ashcraft, McLain, and Eger (2016) report that there is evidence that suggests how workplace conditions, access to innovative vital roles, and a sense of being stalled in their career are just a few of the contributing factors of women leaving the IT and business automation fields. When women are delayed at mid-career without the ability to contribute in the ways they would like, they report higher levels of unhappiness (Burrell, 2019). Hewlett (2008) reported that women are not given access to executing innovation within their roles, which prevents them from getting hands-on experience in innovation and, therefore, are not able to pursue certain IT and business automation occupations. According to Kawamoto (2013), men occupy more roles as business automation administrators, software engineers, and IT managers, while women are more likely to work as project managers or business analysts. The Center for Talent Innovation conducted a study that found that 1 in 3 women in technology reported feeling stalled in their careers and was more likely to quit their job within one year (Hewlett et al., 2014). Forty-six percent of African American women surveyed felt stalled, which was significantly higher than White, Asian, and Latina women (Hewlett et al., 2014). Companies need to address the critical components of attrition and retention if they want to reap the benefits of a more diverse workplace with gender and racial diversity (Burrell, 2019).

The number of companies that say they are committed to gender and racial diversity is vast. Yet, statistics continue to indicate that most are not treating diversity like the business imperative that it is (Thomas et al., 2018). With the competitive nature of the current business environment, finding the right talent is key to immediate and future success (Burrell, 2019). When organizations are not seriously considering half of the population, they are missing out on an immense pool of talent and creativity (Moritz \& Karve, 2017). Organizations must make a genuine, permanent commitment to gender equity and diversity (Burrell, 2019).

\section{The Focus of the Research}

This paper will explore various strategies for incorporation in the areas of cultural change, recruitment techniques, leadership development, and retention that information technology and business automation organizations should adopt to become leaders in gender equity and diversity.

\section{The Purpose of This Research}

The purpose of this research is to understand organizational cultural barriers and challenges that hamper women in business automation and information technology organizations while discovering new strategies for gender diversity and inclusion success.

\section{METHODOLOGY}

The method used is a literature review content analysis of over 101 of the most important and relevant articles concerning women in business automation and information technology with a particular emphasis on those produced and published in the last five years.

\section{Method for Analyzing the Literature}

Research studies and models were selected based on a keywords search for women in technology, women in automation, and women in information technology. Those articles under the search terms that had the highest citation numbers in Google Scholar and Scopus indexes guided the selection of those that were referenced. Additional searches for articles on women in technology and women in information technology included the following databases and their hosts (shown in parentheses): ABI Inform Complete (ProQuest), Academic Search Premier (EBSCO), Business Source Premier 
(EBSCO), ProQuest Dissertations and Thesis Database (ProQuest), Education Research Complete (EBSCO), ERIC (EBSCO), Scopus, and Google Scholar. Usage of these databases allowed a degree of assurance that the data retrieved was authoritative and that the research went through rigid, meticulous, and controlled evaluation systems, which are the brands of scholarly research and writing.

\section{LITERATURE REVIEW}

Organizations that want to commit to creating an enduring environment that promotes gender equality and diversity in the workplace must begin with cultural change (Burrell, 2019). Core values, the dominant values that are accepted throughout the organization, must be firmly in support of gender equality (Robbins \& Judge, 2017, p. 266). Close attention must be given to creating an organizational climate in which the shared perceptions members have about their organization and work environment foster the belief that all highly qualified individuals, no matter the gender, should be treated fairly and be given equal opportunity for development and promotion (Robbins \& Judge, 2017, p. 269). Senior leaders and managers must be champions of diversity and foster a respectful, inclusive culture (Thomas et al., 2018). Research shows that organizations with active cultures of leadership growth also seem to have the highest degree of gender diversity (Coy, 2017).

So, what specific steps can be taken to develop and sustain a culture rich in acceptance of gender diversity? Charles McCoy (2017), author of "Fours Ways Company Culture Can Support Women in Leadership," shares ideas on practices organizations can adopt to foster a culture that supports female employees throughout their career journeys. First, it is imperative to begin with, education; teach all employees about diversity, conflict, and bias (McCoy, 2017). Organizations should create an open but respectful dialogue around controversial topics that shape an individual's unconscious bias so that employee's become self-aware and discover skills to change behaviors and mindsets to encourage a positive shift in attitudes (McCoy, 2017). Second, organizations must listen to their female employees (McCoy, 2017). An environment of open, proactive communication must be fostered, so that female employees feel comfortable sharing career goals and concerns (Burrell, 2019). In truly listening to female employees, organizational leaders can gain valuable insights on how to shape training and create pathways for women to achieve leadership roles (Burrell, 2019).

Unconscious or implicit biases impact women in science and technology fields in cumulative ways. The implicit biases of others may result in explicit or outwardly directed microaggressions that perpetuate stereotypes and lead to environments that are unwelcoming toward women. Females in technology and engineering face even more obstacles than females in other fields, according to McCullough (2011). "They must overcome barriers both in their content area and in leadership areas" (McCullough, 2011, p. 8). A study by Ong, Smith, and Ko (2018) of women of color in STEM higher education settings found that microaggressions are closely linked to feelings of isolation. Some of the microaggressions encountered by women and notably women of color in these environments include hallway displays showing pictures of famous White male scientists, fewer women's bathrooms in science and engineering buildings, and college buildings named after White males (Ong et al., 2018; Dalton \& Villagran, 2018). While institutional microaggressions can be subtle, their effects are significant. Over time, implicit biases and microaggressions may prevent women from pursuing careers in science and technology. They may influence employers in the hiring and evaluation of women in those industries (Hill, Corbett, St. Rose, \& AAUW, 2010, p. 78).

Organizations must work to minimize microaggressions embedded in their corporate cultures that marginalize female employees, especially in fields in which women have been historically underrepresented, such as IT and automation. A study by Aspray and Cohoon (2006) indicated that new female employees in IT companies "tend to face relatively hostile climates" (p. 433). However, when women perceive that their employer values their work and cares about their wellbeing, the results are substantially positive (Aspray \& Cohoon, 2006). Yang and Carroll (2018) noted that leaders must examine the role of gendered microaggressions on the well-being and career 
development of women. For companies seeking to create environments that are inclusive for female employees, awareness training for managers can help to identify and address microaggressions that lead to workplace inequities (Dalton \& Villagran, 2018). Senior leadership must first acknowledge the presence of gendered microaggressions and then seek to lessen their frequency and minimize their impact on women.

\section{Sexual Harassment}

Sexual harassment in business automation and IT fields is perhaps more prevalent than in some other industries where women have more representation (Cole, Burrell, \& Springs, 2020). Since most IT and business automation organizations have a smaller number of women, there is a gross imbalance of gender in the workplace. In industries with fewer women, there are more reported cases of sexual harassment wherein sectors in which women occupy more positions, sexual harassment is lower (Dobbin \& Kalev, 2017). Sexual misconduct and harassment training have been implemented regularly since the 1990s, yet the cases of sexual harassment reported have nearly doubled from 1990 to 2000 and have slowly crept up ever since (Dobbin \& Kalev, 2017). The number of women being sexually harassed in the workplace is often underrepresented since many women fail to report it for several reasons (Cole, Burrell, \& Springs, 2020).

According to Johnson (2008), only $25 \%$ of women report sexual misconduct to their employer due to three main barriers. Women who do complain to their employer fear they will face retaliation, or that they will not be believed (Johnson, 2008). Many are unsure of how to report sexual harassment in their organization. According to Title VII of the Civil Rights Act of 1964, sexual harassment must be deemed extreme or pervasive, so many women fear their case will not legally meet the requirement and do not bother to report it (Cole, Burrell, \& Springs, 2020).

Some politicians are creating laws that help protect the defendant. Kristin Gillibrand, for example, is allowing the victim to go to open court and not be forced into private arbitration, which would allow more public exposure of the sexual offense and enlightens other workers that the complaint was made (Johnson, 2008). Although a good first step, lawmakers need to amend Title VII and clarify what is considered pervasive or severe as currently several offensive behaviors are legally permitted like unwanted touching, name-calling and persistent physical and verbal efforts to coerce others into acts of unwelcome sexual conduct (Cole, Burrell, \& Springs, 2020).

Employers must take sexual harassment seriously (Charlton, 2012). Fostering an environment where all employees feel included, and respected begins with making sure that everyone feels safe (Thomas et al., 2018). Progressive woman-friendly organizations have zero-tolerance policies regarding sexual harassment and gender discrimination (Coles, Burrell, \& Springs, 2020). In doing so, a clear message is sent that the company is not afraid to stand up for its female workers, creating a positive environment for women (Charlton, 2012; Cole, Burrell \& Springs, 2020). Lastly, organizations must create measurable inclusion and diversity goals (McCoy, 2017). It is not enough to talk about inclusion and diversity, and demonstrable progress must be achieved (Moritz \& Karve, 2017). McCoy (2017) suggests that employers, "Track metrics on gender representation of external candidates for hire, salary differences in comparable positions by gender, and assignments of high visibility projects by gender." Implementing these measures will ensure accountability and transparency in reaching gender diversity organizational goals (Burrell, 2019).

Companies need to do more to prevent sexual misconduct in the first place (Cole, Burrell \& Springs, 2020). Most employees have the experience of completing a sexual harassment training in the form of an online course, clicking through a PowerPoint, or signing a multi-page PDF (Cole, Burrell \& Springs, 2020). According to Miller (2017), regular sexual harassment training does not work, but strategies such as training bystanders to intervene can be much more effective. Promoting women in the IT and business automation fields can help counteract incidents of sexual misconduct by shifting the balance of power. Sexual harassment is a power issue where the offender exhibits control over his victim (Cole, Burrell \& Springs, 2020). By empowering the bystanders to stand up 
for the victim, it takes power away from the offender. Bystander training has been implemented in the armed forces and on college campuses, but it is still rare in the corporate world (Miller, 2017), where most business automation technology jobs reside. Some of the bystander training suggests that witnesses can call out the behavior during the time of the incident, or they can intervene by creating a loud distraction or trying to get the victim to another location, such as calling them to an impromptu meeting in a conference room (Cole, Burrell, \& Springs, 2020). Other ideas include confronting the perpetrator and call them out on their language or behavior and informing them that it was inappropriate (Cole, Burrell, \& Springs, 2020). When bystanders remain silent, the offender gains more power over the relationship, so bystander training can be highly effective in preventing the behavior from reoccurring (Cole, Burrell, \& Springs, 2020).

Organizations with inclusive cultures have women represented in all job roles and at all levels in the organization (Burrell, 2019). When companies have more women in management, they also have less sexual harassment than organizations in which there are too many men in positions of power, since they often enable each other's behavior. After all, they feel pressured to accept the behavior (Miller, 2017). One of the primary reasons companies fail to promote women in positions of power is because "they often leave industries where sexual harassment is common and goes unaddressed" (Dobbin \& Kalev, 2017). Equal pay and equal promotion of both genders help. Still, if companies are not actively recruiting women through colleges or providing mentors when hired, they lose out on the ability to attract and retain top female talent in IT and automation (Burrell, 2019). When companies employ college recruitment strategies, they gain significantly, which helps tip the balance of power and can slowly eradicate sexual misconduct in the workforce. According to Dobbin and Kalev (2016), five years of college recruitment programs aimed at targeting women resulted in an average of $10 \%$ increase in management roles. Additionally, a program that focuses specifically on minority recruitment can see an increase of $9 \%$ of black female managers on average (Dobbin \& Kalev, 2016).

\section{Recruitment}

When it comes to recruiting qualified female candidates, organizations must ensure that hiring and promotional practices are consistent and fair (Burrell, 2019). Effective female recruiting must begin with properly training recruitment professionals on implementing more inclusive strategies (Moritz $\&$ Karve, 2017). First and foremost, company recruiters must examine and remove any subconscious biases that may stand in the way of embracing inclusiveness and diversity in hiring practices (Barry, 2018). They must be taught that recruiting, hiring, and retaining women is an essential goal for the organization, and each member of the team must share this vision (Charlton, 2012).

Job descriptions should be reviewed for language that may indicate gender-bias, and whenever possible, the stereotypical language should be changed (Burrell, 2019). In the article "Recruit and Retain Women in the Workforce," Sami L. Barry (2018) shares, "When gender-biased language is removed from job postings, statistics show the applicant pool typically increases by 42 percent." Interviewers and interview panels must demonstrate diversity by including female members, resulting in a more welcoming setting for all candidates (Burrell, 2019).

To reach higher numbers of qualified female candidates, organizations must "spread their recruiting net" (Charlton, 2012). Companies need to focus on reaching women where women are, namely women's colleges, women's philanthropic organizations, social media platforms, and women's networking organizations and career websites (Burrell, 2019).

Finally, an enticing way to recruit qualified women to become a part of any company's workforce is to offer benefits and flexibility to "fit work into their lives" (Thomas et al., 2018). Robbins and Judge (2017) support this idea through the use of flexible benefits, a plan that allows employees to put together a benefits package that more precisely meets his or her own needs and personal situation (p. 133). When making a career choice, having an array of benefit options that more personally fit a female candidate's lifestyle and needs may be the deciding factor in choosing an organization to become a part of and may also help to retain valued employees (Burrell, 2019). 


\section{Development}

Organizations must not rest once they successfully put into place a culture of inclusion and successful recruitment strategies (Burrell, 2019). To sustain the culture of valuing gender diversity in the workplace, companies must also focus on the continuous development of female employees (Burrell, 2019). Organizations can not only strive to hire women; they must also look to promote and develop women for leadership roles (Burrell, 2019). Companies must endeavor to find not only experienced candidates but also potential growth within their new hires and current employees (Burrell, 2019).

Employing a diversified leadership team is significant because it demonstrates to talented women that the organization is a place where opportunities to advance to high-level positions are available (Burrell, 2019). Therefore, structured development and mentorship programs are vital in building leadership skills and characteristics in female employees (Burrell, 2019).

Angela Grosvenor (2017), author of the article "Time to Get with It: Creating Successful Women's Leadership Programs," outlines multiple benefits of implementing a women's leadership development program within any organization. First, by confronting the gender gap and making efforts to appeal to and retain female talent through leadership development programs, companies will be better prepared to take advantage of a larger pool of emerging leaders (Grosvenor, 2017). Secondly, having women in top leadership positions can mean a more diverse team of leaders with different perspectives who can contribute new ideas (Grosvenor, 2017). Third, having both men and women in leadership helps organizations reflect the customers served, giving a more well-rounded perspective and leading to increased sales and company growth (Grosvenor, 2017). Last, and possibly most important, organizations that create a culture of equal opportunity and diversity are better able to attract, retain, and motivate the most qualified individuals (Grosvenor, 2017).

The benefits of developing leadership programs for women are clear, but what should be their focus? As with many leadership development programs, traditional topics should be covered, including strategic thinking, delegation, team-building, emotional intelligence, and communication skills (Grosvenor, 2017). In addition to the tried and true themes, the following subjects tend to be very useful and relevant for women seeking leadership positions: enhancing personal influence in the organization, essential skills matched to leadership challenges, the art of negotiation, conflict management, and resolution, and improvement of business acumen specifically focused on financial monitoring and reporting, goal setting, talent management, and evaluation (Grosvenor, 2017). Developing all leaders from all genders is essential in the workplace, but gender diversity and inclusion requires emphasis (Burrell, 2019). Organizations must devote time, personnel, and resources to the implementation of innovative women's leadership development programs (Burrell, 2019).

Organizations should also consider implementing mentorship programs as part of the leadership development process of female employees (Burrell, 2019). Mentors, as defined by Robbins and Judge (2017), are senior employees who sponsor and support a less experienced colleague (p. 203). Mentorships are more personalized relationships between employees that serve both career and psychosocial functions (Robbins \& Judge, 2017, p. 203). Successful mentors are role models for their protégés. They introduce ideas, are good listeners, and empathize (Robbins \& Judge, 2017, p. 203). Mentorship programs are of great benefit to inclusive cultures because they emphasize integrity and collaboration and encourage support resulting in an environment where all may achieve their potential (Coy, 2017).

Mentorship programs are also an excellent way to cultivate the talent and skills already available within the organization (Burrell, 2019). Pairing up new hires with higher-level executives can be a win-win for both sides of the partnership (Burrell, 2019). Building leaders, by example, is vital (Burrell, 2019). Moritz and Karve (2017), in the article "5 Strategies for Finding-and-Keeping-Female Talent", share that a large percentage of women, when asked, say they consider positive role models when deciding to accept a position with an employer.

In conclusion, women leaders have a vital role to play by creating equality at the top, inspiring other women, and helping them to reach their full potential (Moritz \& Karve, 2017). The evidence 
is clear. An investment in both company-wide programs and mentorship opportunities to train and prepare women for leadership positions is essential when it comes to increasing the number of women in leadership roles (Burrell, 2019).

\section{Gender Pay Gap}

The gender pay gap is still an essential component to exploring how to hire, train, and promote women in IT and automation fields. The gender pay gap is the difference between the average wage of all men and all women, regardless of job type or employee seniority (O'Neill, 2019). In 2019, women were still only earning 79 cents for every dollar earned by men, and women tend to be overrepresented in lower-paying fields like home health care and underrepresented in higher-paying fields such as computer science (Gender Pay Gap Ratios, 2019). Computer science is grossly dominated by men who occupy $76 \%$ of all positions making the female representation about 24\% (Gender Pay Gap Ratios, 2019). Being so significantly outnumbered, women may focus on job security rather than salary negotiation. Dawson (2017) posited that it was standard behavior for women not to negotiate their salary. Women can appear to be content with making less for several reasons, and in grossly underrepresented industries, they may have imposter syndrome. "Impostor is a psychological pattern in which one doubts one's accomplishments and has a persistent internalized fear of being exposed as a fraud" (Langford, Clance, Pauline, 1993). Imposter syndrome is the idea that you are not good enough to be in a position of power or that you do not measure up to others, which is more likely to affect women than men, especially in the technology and automation fields (Mullangi \& Jagsi, 2019). When women experience imposter syndrome, it can cause their careers to stagnate (Mullangi \& Jagsi, 2019). Women may not go after higher-paying internal or external positions, making it harder for companies to find executive-level female leadership (Mullangi \& Jagsi, 2019). When more women occupy underrepresented roles, such as in IT and automation, their feelings of inadequacy may improve because more female-to-female mentorship opportunities can occur (Mullangi \& Jagsi, 2019). Robbins and Judge (2017) articulated that there are numerous benefits of mentorship in the shaping of future female leaders through the development of healthy cultures that value and acknowledge the talents, expertise, and accomplishments of women. These are organizational cultures where women are visible in significant projects and job roles where they become inspirational role models for other women (Burrell, 2019).

\section{Gender Pay Disparities}

Industries that can unionize have a smaller gap in pay between genders. Still, women are less likely to be in union roles making the disparity between unionized males and ununionized females the greatest of all (Meara, Pastore \& Webster, 2020). Women in technology and automation are grossly underpaid compared to their male counterparts (Taylor, 2019). Yet, they also rarely progress to the same levels of stature and responsibility, making valid comparisons difficult (Taylor, 2019). According to a study done by the recruitment firm Hired, more than half of all women in the tech field earn less than their male counterparts, and $16 \%$ made more than $\$ 20,000$ less than men with the same position (Taylor, 2019). In the United States, the gender pay gap hovers at around 3\%, but Latin American women in tech are the most underpaid compared to men nationally at $9 \%$ less than White males. Oddly some of the biggest hubs for technology and business automation, which include New York City, Seattle, and Los Angeles, have more significant gender pay gaps than the national average with $9 \%$ overall (Taylor, 2019). Adjusting the gender pay gap is as much a statewide issue as it is a nationwide one (Taylor, 2019).

According to Dawson (2018), there are underlying psychological differences in men and women that contribute to the pay gap. For example, women often focus on job flexibility. In contrast, men usually focus solely on pay, and women are more risk-averse compared to men, often not going after competitive positions and taking less pay as a result (Dawson, 2018). Women usually stay in their roles rather than scale the ladder to executive-level leadership partly because some women lack 
confidence and underestimate their abilities making them complacent and generally satisfied with the pay differences (Dawson, 2017). Women often stagnate in their roles, but if they do not search for new jobs or ask for a promotion, they cannot improve upon their pay. Dawson (2018) also found in a 2017 study that men often overestimated their abilities, and women underestimated theirs, which prevents the pay gap from becoming significantly smaller. One strategy employers can use is to actively promote women from lower ranks into higher executive levels rather than wait for them to apply since they may never even seek these positions (Dawson, 2017).

When companies are transparent about their gender pay gap, they see the difference close more aggressively, and companies that are subject to a regulation that forces them to disclose wages are more likely to hire and promote more women (Bennedsen, Simintzi, Tsoutsoura, \& Wolfexnon, 2019). Transparency in salaries is beneficial to the equality of women and minority women in the workplace, but it is not the only way to close the gender pay gap. Fighting gender bias is a major contributing factor to improving pay differences, and promoting a culture of mentorship from female as well as male employees can also help (Why closing the gender pay gap matters, n.d.). Making these changes is not as easy as it involves changing company culture. Still, when companies change their culture, they shift their focus to a more equality-driven workplace that can reap the numerous benefits of a diverse workforce (Cole, Burrell \& Springs, 2020).

\section{Retention}

Once the organizational culture, recruitment, and development practices are firmly in place to support and promote women into leadership roles, the question remains; what steps should companies take to retain these valuable employees? To adequately address the problem, organizations need to recognize, as Sally Blount (2017) explains, the "pivot points" or decision points where women face unique issues that may result in some high-potential women making trade-offs affecting the potential upward mobility in their careers. By finding ways to support female employees through these pivot points, employers may be able to increase the likelihood of retention and flow into senior leadership positions (Blount, 2017).

The first pivot point, as Blount (2017) describes it, is The Launch. At the beginning of their careers, female college graduates tend to earn less than their male counterparts; specifically, studies show that on average, women earn about $80 \%$ of what their male peers do (Blount, 2017). Also, young women starting in the workforce are often more exposed to the negative stereotypes of not feeling "as qualified" as their male colleagues, possibly leading to the decision to abandon their current career path (Blount, 2017). To combat these problems, it is crucial for organizations to uphold the culture of gender diversity and inclusion, be in constant review of the measurable metrics in place to combat pay disparities, and have female role models in upper management who can demonstrate a meaningful career in business (Burrell, 2019).

Blount (2017) calls the second pivot point The Mid-career Marathon. During the Midcareer Marathon, women have moved into a time of their lives where relationship and caregiving responsibilities come into significant focus. Whether by choice or by necessity, Blount (2017) shares that studies find women typically pick up more of the burdens for meeting their family's growing needs, sometimes leading to a decision to step away from their developing careers. To prevent this from happening, employers must offer a more tailored suite of benefits, including flexible working hours, job share capabilities, and untraditional career paths (Burrell, 2019). Career transition periods, such as this pivot point, offer an optimal phase in which to utilize mentoring programs to assist midcareer women in navigating the stress while sustaining professional goals (Burrell, 2019).

The final pivot point introduced by Blount (2017) is The Executive Transition. Women who have arrived at this pivot point have successfully made it through the Launch and Mid-career Marathon and are on the horizon of transitioning into top leadership roles, but either by chance or by choice, many of these women never leap (Blount, 2017). Usually, if the failure to transition is not made by chance, it is because of, once again, some type of internal bias that is preventing the promotion 
(Blount, 2017). If the failure to transition is not made due to personal choice, it is likely because she has determined the reward is no longer a motivating factor. For highly successful women to move past this point, there must be a combination of proper motivation and opportunity (Blount, 2017). Having a healthy organizational culture is a critical aspect of employee retention and job satisfaction (Burrell, 2019). Organizations must stay vigilant and accountable for gender diversity goals and elimination of underlying biased practices, along with maintaining focus on career development opportunities and coaching (Burrell, 2019).

The process for creating an increased pipeline for employing and retaining highly qualified women within an organization begins with every new hire (Burrell, 2019). Companies must have a thriving gender-inclusive culture, mentoring, and development programs to offer support, flexibility in career pathways, and motivating factors guiding skilled women to genuine opportunities in achieving leadership positions (Burrell, 2019).

\section{CONCLUSION}

A critical part of addressing these issues includes engaging in various levels of assessment (Cole, Burrell \& Springs, 2020). This assessment consists of comparing the number of female employees in the department with the population of women in the community and the overall population in the city in ways that also examine data about women of different races and ethnic backgrounds. Another part of the assessment process includes looking at the percentage of women in management and comparing that to the overall population of women in the organization. Logic would assume, for example, if $20 \%$ of the employees are women, then $20 \%$ of the managers are women. This assessment focus is on ensuring that numbers are in proportion. The final element of the assessment process includes having women employees or all employees engaging in a workplace climate or workplace assessment survey like the one below (Cole, Burrell \& Springs, 2020).

\section{Burrell Valued Diversity Equity and Civil Workplace Assessment Survey (2016)}

Are you? Please check the correct box

Male or Female

Using the 5-point scale below, rate each question based on your organization's level of engagement:

$5=$ Frequent level

$4=$ Reasonable level

$3=$ Fair level

$2=$ Infrequent level

$1=$ Never

1. To what extent do you feel that a clear and openly publicized mission statement regarding equity and inclusion regarding culture, gender, race, religion, national origin, age, socioeconomic status, and disability?

2. To what extent do you feel that your organization's culture and supervisors support you in terms of your ability to be open and honest about your culture, gender, race, religion, national origin, age, socioeconomic status, and disability (if relevant)?

3. To what extent do you feel that your management and organizational leadership has a zerotolerance approach to concerns and issues related to offenses towards others around bullying, harassment, discrimination, and prejudice regarding your culture, gender, race, religion, national origin, age, socioeconomic status, and disability (if relevant)? 
4. To what extent do you feel that the supervisors and organization have policies, sets consistent expectations, rules, and consequences against behaviors that are non-biased regarding culture, gender, race, religion, national origin, age, socioeconomic status, and disability?

5. To what extent do you feel that tasks, visible project leadership roles, and significant training and professional development opportunities are distributed equitably by supervisors without regard to gender, race, national origin, or disability?

6. To what extent do you feel that your supervisors and organizational leadership show authentic concern against the use of non-biased verbal and nonverbal language by employees in the organization regarding culture, gender, race, religion, national origin, age, socioeconomic status, and disability?

7. To what extent do your supervisors and organizational leadership encourage an organizational environment where commonalities are appreciated, and differences are understood and valued regarding culture, gender, race, religion, national origin, age, socioeconomic status, and disability?

8. To what extent do you feel that the behaviors and actions of your co-workers towards you match with the written values and mission of the organization around diversity, equity, inclusion?

9. To what extent do you feel that the organizational policies are relevant and fair as it relates to someone of your culture, gender, race, religion, national origin, age, socioeconomic status, and disability (if relevant)?

10. To what degree do you feel that organizational leaders are engaged in authentic actions, policies, and initiatives to ensure highly qualified members different cultures, genders, races, religions, ethnic backgrounds, or disabilities distributed equitably or constructively represented across the various job classifications from management to technical staff positions.

\section{Scoring Scale Burrell Valued Diversity Equity and Civil Workplace Assessment Survey (Table 1)}

The days of filling gender disparities in the workplace by hiring one or two qualified females to fill integral roles within an organization have come and gone (Burrell, 2019). Employers must make gender diversity and inclusion a real business priority (Burrell, 2019). This begins with setting specific goals and holding leaders accountable for results. It requires closing gender gaps in hiring

Table 1. Score results

\begin{tabular}{|l|l|}
\hline 41-50 points & $\begin{array}{l}\text { It seems extremely likely that diverse personnel, those of different cultures, genders, races, } \\
\text { religions, ethnic backgrounds, or disabilities, in the organization feel much respected and highly } \\
\text { valued in the organizational culture by both their management and their co-workers. }\end{array}$ \\
\hline 31-40 points & $\begin{array}{l}\text { It seems very likely that diverse personnel, those of different cultures, genders, races, religions, } \\
\text { ethnic backgrounds, or disabilities, feel respected and valued to a certain degree in the } \\
\text { organizational culture by both their management and their co-workers. }\end{array}$ \\
\hline 21-30 points & $\begin{array}{l}\text { It seems somewhat likely that diverse personnel, those of different cultures, genders, races, } \\
\text { religions, ethnic backgrounds, or disabilities, feel marginally respected and valued in the } \\
\text { organizational culture by both their management and their co-workers. }\end{array}$ \\
\hline $11-20$ points & $\begin{array}{l}\text { It seems minimally likely that the prevailing feeling on the part of diverse personnel, those of } \\
\text { different cultures, genders, races, religions, ethnic backgrounds, or disabilities, is that their } \\
\text { expertise and work contributions are not respected and valued in the organizational culture by } \\
\text { both their management and their co-workers. }\end{array}$ \\
\hline 0-10 points & $\begin{array}{l}\text { Diverse employees likely have adverse feelings about workplace civility, workplace culture, } \\
\text { management, and co-workers in terms of respectful behaviors, values, policies, and procedures } \\
\text { regarding different cultures, genders, races, religions, ethnic backgrounds, or disabilities. } \\
\text { In 2016 by Darrell Norman Burrell developed an organizational process as a result of research } \\
\text { done in conjunction with a graduate capstone project at Claremont Lincoln University. }\end{array}$ \\
\hline
\end{tabular}


and promotions, including decisions made early in the pipeline when many talented women are often overlooked, and it means employers must take bolder steps to create respectful and inclusive workplaces (Thomas et al., 2018).

Studies have repeatedly shown that significant impacts can be made by employing and retaining highly skilled women (Burrell, 2019). Barry (2018) supports this theory by sharing survey results from the Peterson Institute for International Economics, which surmised having more female leaders in high levels of corporate management correlates with increased profitability. Therefore, one can undoubtedly conclude closing the corporate gender gap is not a fleeting thought; it is an economic necessity (Thomas et al., 2018). Rachel Thomas et al. (2018) beautifully summarizes the importance of gender diversity in the workplace by saying, "Programs and policies designed to reduce bias and ensure fairness don't just benefit women. They benefit everyone. In the best workplaces, the most talented people can rise, no matter who they are. That should be the expectation for every workplace, everywhere."

\section{Areas of Future Research}

Several possible components hold women back from attaining leadership positions in information technology and computer science. Yet, there is very little research that has investigated what those components are at various stages of career, including entry-level, mid-career, and senior-level (Burrell, 2019). It is assumed that the lack of female executive leadership is cumulative and incremental, resulting in women dropping out of the technology industry at different points (Ahuja, 2002). Uncovering the psychological, cultural, socio-economic, and societal reasons why women drop out of the IT and automation fields would be beneficial to understanding the lived experience of women making these choices (Burrell, 2019).

Furthermore, a study that seeks to understand how career persistence and career advancement affect the outcome of finding executive-level leadership positions for women would benefit the quest for knowledge in this topic area. The perspectives of female leaders need to be heard to understand the critical components of career attrition and retention and the reasons why certain females have progressed to the c-level suite. Additionally, questions could be asked in an open-ended survey that would seek to find out if each woman felt she was paid fairly for her position, if she was in a desirable job or if she felt stagnated and why.

Another study that would benefit the understanding of gender disparity in IT would be to conduct a case study involving one IT industry leader's attempt to increase female leadership through mentoring and professional development for women, such as leadership training or other programming, which could provide useful statistical data on the outcome of such initiatives in IT. Additionally, a metaanalysis or quantitative study should be done to investigate data on female leaders' career progression, education attainment, decisions, and timings of starting a family and demographic information such as details about her support system, her parents' economic status, and her parents' education level.

In conclusion, although there is a vast amount of research done on the gender pay gap and some issues of inequality, there is still more work to be done, especially in grossly underrepresented industries such as computer science, engineering, and architecture. 


\section{REFERENCES}

Ahuja, M. K. (2002). Women in the information technology profession: A literature review, synthesis, and research agenda. European Journal of Information Systems, 11(1), 20-34. doi:10.1057/palgrave.ejis.3000417

Ashcraft, C., McLain, B., \& Eger, E. (2016). Women in tech: The facts. National Center for Women \& Technology. NCWIT.

Aspray, W., \& Cohoon, J. M. (2006). Women and Information Technology: Research on Underrepresentation. The MIT Press.

Ballenger, J., Polnick, B., \& Irby, B. J. (2017). Women of Color in STEM: Navigating the Workforce. Information Age Publishing.

Barry, S. (2018, April 24). Recruit and retain women in the workforce. Construction Executive. Retrieved from https://constructionexec.com/article/recruit-and-retain-women-in-the-workforce

Bennedsen, M., Simintzi, E., Tsoutsoura, M., \& Wolfenzon, D. (2019). Do firms respond to gender pay gap transparency? National Bureau of Economic Research.

Blount, S. (2017, March 16). Getting more women into the C-suite means keeping them in the talent pipeline. Kellogg Insight. Retrieved from https://insight.kellogg.northwestern.edu/article/getting-more-women-into-thec-suite-means-keeping-them-in-the-talent-pipeling

Burrell, D. (2019) Developing more Women in Managerial Roles in Information Technology and Cybersecurity. In MWAIS 2019 Proceedings. Academic Press. https://aisel.aisnet.org/mwais2019/20

Charlton, D. (2012, November 8). 5 keys to recruiting women for your workforce (Binders are optional). TLNT Talent Management \& HR. Retrieved from https:/www.tlnt.com/5-keys-to-recruiting-women-for-your-workforcebinders-are-optional/

Cole, C., Burrell, D., \& Springs, D. (2020). Exploring Organizational Development Intervention Around Sexual Harassment in Technical Firms. International Journal of Hyperconnectivity and the Internet of Things, 4(1), 29-42. doi:10.4018/IJHIoT.2020010103

Coy, C. (2017, May 4). Four ways company culture can support women in leadership. ReWork. Retrieved from https:/www.cornerstoneondemand.com/rework/four-ways-company-culture-can-support-women-in-leadership/

Dalton, S., \& Villagran, M. (2018). Minimizing and addressing microaggressions in the workplace: Be proactive, Part 2. College \& Research Libraries News, 79(10), 538-564. doi:10.5860/crln.79.10.538

Dawson, C. (2017). The upside of pessimism- Biased beliefs and the paradox of the contented female worker. Journal of Economic Behavior \& Organization, 135, 215-228. doi:10.1016/j.jebo.2017.02.004

Dawson, C. (2018, September 19). Why women and men too easily accept the gender pay gap. The Conversations. Retrieved from https://theconversation.com/why-women-and-men-too-easily-accept-the-gender-pay-gap-73535

DeLeon, M. (2014, October 21). How to recruit more female executives. Entrepreneur. Retrieved from https:// www.entrepreneur.com/article/238743

Dobbin, F., \& Kalev, A. (2016). DIVERSITY why diversity programs fail and what works better. Harvard Business Review, 94(7-8), 52-60. PMID:27491195

Dobbin, F., \& Kalev, A. (2017). Training programs and reporting systems won't end sexual harassment. Promoting more women will. Harvard Business Review, 70(4), 687-702.

Finland to give dads same parental leave as mums. (2020, February 5). Retrieved from https://www.bbc.co.uk/ news/world-europe-51384614

Gender Pay Gap Ratios, Stats, and Infographics 2019. (n.d.). Retrieved from https://www.payscale.com/data/ gender-pay-gap

Global Strategy Group. (2017, July 28). Women in leadership: Tackling corporate culture from the top. Rockefeller Foundation. Retrieved from https://assets.rockerfellerfoundation.org/app/uploads/20170728121141/women-inLeadership-Tackling-Corporate-Culture-from-the-Top.pdf 
Grosvenor, A. (2017, July 6). Time to get with it: Creating successful women's leadership programs. Huffington Post. Retrieved from https:/www.huffingtonpost.com/entry/time-to-get-with-it-creating-successful-womensleadership_us_595e4260e4b08f5c97d06775

Hewlett, S. A., Buck Luce, C., Servon, L., Sherbin, L., Shiller, P., Sosnovich, E., \& Sumberg, K. (2008). The Athena factor: Reversing the brain drain in science, engineering, and technology. New York: Center for Worklife Policy. Retrieved from http://www.talentinnovation.org/publication.cfm?publication=1100

Hewlett, S. A., \& Sherbin, L. with Dieudonné, F., Fargnoli, C., \& Fredman, C. (2014). Athena Factor 2.0: Accelerating female talent in science, engineering, \& technology. Center for Talent Innovation. Retrieved from http://www.talentinnovation.org/publication.cfm?publication=1420

Hill, C., Corbett, C., St. Rose, A., \& American Association of University Women. (2010). Why So Few? Women in Science, Technology, Engineering, and Mathematics. American Association of University Women.

Johnson, M. E. (2018). Only 1 in 4 women who have been sexually harassed tell their employers. Here's why they're afraid.

Kuschel, K. (2019). Women Founders in the Technology Industry: The Startup-Relatedness of the Decision to Become a Mother. Administrative Sciences, 9(2), 30. doi:10.3390/admsci9020030

Kuschel, K., \& Labra, J. P. (2018). Developing Entrepreneurial Identity among Start-ups' Female Founders in High-Tech: Policy Implications from the Chilean Case. In P. G. Greene \& C. G. Brush (Eds.), A Research Agenda for Women and Entrepreneurship: Identity through Aspirations, Behaviors, and Confidence (pp. 27-44). Boston: Edward Elgar. doi:10.4337/9781785365379.00007

Langford, J., \& Clance, P. R. (1993, Fall). The impostor phenomenon: Recent research findings regarding dynamics, personality and family patterns and their implications for treatment. Psychotherapy, 30(3), 495-501. doi:10.1037/0033-3204.30.3.495

McCullough, L. (2011). Women's Leadership in Science, Technology, Engineering, and Mathematics: Barriers to Participation. Forum on Public Policy Online, (2).

McGinley. A.C. (2014). Title VII at Fifty Years: A Symposium. Nevada Law Journal, 14(3).

McGregor, J. (2017, October 23). How most leadership training programs fail women. The Washington Post. Retrieved from https://www.washingtonpost.com/news/on-leadership/wp/2017/10/23/how-most-leadershiptraining-programs-fail-women/

Meara, K., Pastore, F., \& Webster, A. (2020). The gender pay gap in the USA: A matching study. Journal of Population Economics, 33(1), 271-305. doi:10.1007/s00148-019-00743-8

Miller, C. C. (2017, December 11). Sexual Harassment Training Doesn't Work. But Some Things Do. New York Times. Retrieved from https://www.nytimes.com/2017/12/11/upshot/sexual-harassment-workplace-preventioneffective.html

Moritz, B., \& Karve, S. (2017, March 8). 5 strategies for finding - and - keeping - female talent. World Economic Forum. Retrieved from https://www.weforum.org/agenda/2017/03/5-strategies-for-winning-thefight-for-female-talent/

Mullangi, S., \& Jagsi, R. (2019). Imposter syndrome: Treat the cause, not the symptom. Journal of the American Medical Association, 322(5), 403-404. doi:10.1001/jama.2019.9788 PMID:31386138

Mussino, E., Tervola, J., \& Duvander, A. Z. (2019). Decomposing the determinants of fathers' parental leave use: Evidence from migration between Finland and Sweden. Journal of European Social Policy, 29(2), $197-212$. doi:10.1177/0958928718792129

O’Neill, S. (2019). Gender pay gap grows. New Scientist, 241(3223), 45. doi:10.1016/S0262-4079(19)30563-9

Ong, M., Smith, J. M., \& Ko, L. T. (2018). Counterspaces for Women of Color in STEM Higher Education: Marginal and Central Spaces for Persistence and Success. Journal of Research in Science Teaching, 55(2), 206-245. doi:10.1002/tea.21417

Robbins, S. P., \& Judge, T. A. (2017). Essentials of organizational behavior (14th ed.). Boston, MA: Pearson. 
Simard, C., Davies Henderson, A., Gilmartin, S., Schiebinger, L., \& Whitney, T. (2008). Climbing the technical ladder: Obstacles and solutions for mid-level women in technology. Palo Alto, CA: Anita Borg Institute and Clayman Institute; Retrieved from http://anitaborg.org/wp-content/uploads/2013/12/Climbing_the_Technical_ Ladder.pdf

Taylor, C. (2019, March 28). US tech still has a pay discrimination problem, research shows. CNBC. Retrieved from https://www.cnbc.com/2019/03/28/us-tech-still-has-a-pay-discrimination-problem-research-shows.html

Thomas, R. (2018). Women in the workplace 2018. Lean In. Retrieved from https://womenintheworkplace.com

Why closing the gender pay gap matters. (n.d.). Retrieved from https://leanin.org/equal-pay-data-about-thegender-pay-gap

Yang, Y., \& Carroll, D. W. (2018). Gendered Microaggressions in Science, Technology, Engineering, and Mathematics. Leadership and Research in Education, 4, 28-45. Retrieved from https://files.eric.ed.gov/fulltext/ EJ1174441.pdf

Darrell Norman Burrell is post graduate student and a 2017 graduate of the National Coalition Building Institute's (NCBI) Leadership Diversity Institute. He is a Certified Diversity Professional. He is an alumnus of the prestigious Presidential Management Fellows Program www.pmf.gov. Dr. Burrell has a doctorate degree with majors in Education and Executive Leadership Coaching from A.T. Still University. Dr. Burrell has an Education Specialist (EdS) graduate degree in Higher Education Administration from The George Washington University. He has two graduate degrees one in Human Resources Management/Development and another Organizational Management from National Louis University. He also has a Master of Arts degree in Sales and Marketing Management from Prescott College. He has extensive years of university teaching experience at several universities.

Dawn DiPeri graduated in December 2019 with a Doctor of Management with a concentration in Higher Education, Teaching and Learning from Colorado Technical University. She also has a Master of Fine Arts in Advertising from Academy of Art University and a Bachelor of Technology in visual communications from SUNY Farmingdale. Dawn has been teaching face to face, hybrid and online since 2012 and is actively teaching at American InterContinental University in the general education department. Dawn also has experience teaching for a community college, and two private liberal arts universities in the New York area in the areas of education, communications and technology. Dawn also owns an award-winning branding/advertising agency since 2012 where she specializes in servicing the non-profit and education sector providing management consultation and graphic design services. Her research interests are centered around institutional effectiveness and ed tech.

Rachel Weaver holds graduate degrees in Teacher Leadership and Education and maintains six teaching certifications. With more than twelve years of experience in K-12 environments, Dr. Weaver has been recognized as a Distinguished Teacher in Elementary Education by the American Board for the Certification of Teacher Excellence and has served as a Pennsylvania Delegate to the Mickelson ExxonMobil Teacher Academy. She has been the recipient of numerous grants to implement technology in traditional classroom settings, as well as non-traditional settings such as a juvenile justice education program. She has presented about classroom technology in various forums, including the Western Governors University Teachers College Summit and the Connelly Foundation Idea Incubator. Dr. Weaver works with student teachers as a Site Supervisor for Grand Canyon University. Additionally, she teaches graduate and undergraduate courses in Education at Western Governors University, where she serves as the Subject Matter Expert on Diversity and Inclusion. Dr. Weaver's current areas of research include implicit bias and microaggressions. 